\title{
Magnetic and electronic properties of lithium cobalt oxide substituted by nickel
}

F Gendron, a, S Castro-Garcia ${ }^{b}$, E Popova ${ }^{c}$, S Ziolkiewicz ${ }^{a}$, F Soulette ${ }^{a}$, C Julien $^{\mathrm{a}}$

a Laboratoire des Milieux Désordonnés et Hétérogènes, UMR7603, Université Pierre et Marie Curie, 4 place Jussieu, case 86, 75252 Paris cedex 05, France

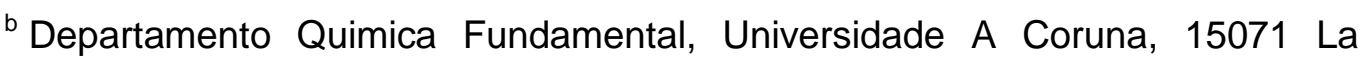
Coruña, Spain

' Laboratoire de Magnétisme et Optique, Université de Versailles-CNRS, 45 av. des Etats-Unis, 78035 Versailles, France

Solid State Ionics

Volume 157, Issues 1-4, February 2003, Pages 125-132

Proceedings of the 6th International Symposium on Systems with Fast lonic Transport (ISSFIT)

Received 21 May 2001, Revised 25 January 2002, Accepted 31 January 2002, Available online 14 May 2002

doi:10.1016/S0167-2738(02)00198-4

\section{Abstract}

We measured susceptibility, electron-spin resonance, magnetization and electrical conductivity of $\mathrm{LiC}_{1-}-\mathrm{NNi}_{\mathrm{N}} \mathrm{O}_{2}$ powders synthesized by wet-chemistry method using succinic acid as chelating agent. We found unusual properties in the nickel-rich $\mathrm{LiCO}_{0.2} \mathrm{Ni}_{0.8} \mathrm{O}_{2}$, which shows several resonance lines as a function of the temperature in the range $3.5-300 \mathrm{~K}$. The signal at low magnetic field is attributed to the magnetic domains in the nanostructured sample. The two other lines correspond to the typical ferromagnetic signal observed in powdered compounds. In the temperature range 120- 
$300 \mathrm{~K}$, the unique ESR line centered at $315 \mathrm{mT}$ is the paramagnetic signal with a gyromagnetic factor $g=2.12$, which is in good agreement with the presence of a high concentration of $\mathrm{Ni}^{3+}\left(3 \mathrm{~d}^{7}\right)$ ions. In the nickel-rich oxide, $\mathrm{LiNi}_{0.8} \mathrm{Co}_{0.2} \mathrm{O}_{2}$, the magnetic data are qualitatively well-described by the model proposed by Drillon and Panissod for a 3D ferromagnetic order.

\section{Keywords}

Electron-spin resonance; Wet-chemistry; Ferromagnetic order

\section{Introduction}

With the successful development of several lithium insertion compounds, the commercialization of rechargeable Li-ion batteries was realized with lithiated transitionmetal oxides (LTMOs) including either $\mathrm{LiCoO}_{2}$ or $\mathrm{LiMn}_{2} \mathrm{O}_{4}$ cathode materials [1]. However, it has been shown that the use of $\mathrm{LiCo}_{1}-y \mathrm{Ni}_{2} \mathrm{O}_{2}$ solid solution allowed subsequent electrochemical improvement due to the structural stabilization of the layered structure [2].

The crystal structure of $\mathrm{LiCo}_{1}-\mathrm{yNi}_{\mathrm{NO}}$ oxides is called the $\alpha-\mathrm{NaFeO}_{2}$ type, which has a rhombohedral $\mathrm{R} 3 \mathrm{~m}$ symmetry. This is a modified $\mathrm{NaCl}$ structure in which closely packed triangular lattices of each kind of atom are stacked in layer order $\left(\mathrm{Co}_{1}-y \mathrm{Niy}\right), \mathrm{O}$, $\mathrm{Li}, \mathrm{O}$, and $\left(\mathrm{Co}_{1-y \mathrm{Niy}}\right)$ with $\mathrm{ABC}$ stacking [3]. In this structure, lithium ions occupy the octahedral sites between $\left(\mathrm{Co}_{1}-y \mathrm{Ni}_{2} \mathrm{O}_{2}\right) n$ infinite slabs formed by edge-sharing $\left(\mathrm{Co}_{1-\mathrm{yNiy}}\right) \mathrm{O}_{2}$ octahedra as shown by the schematic representation in Fig. 1.

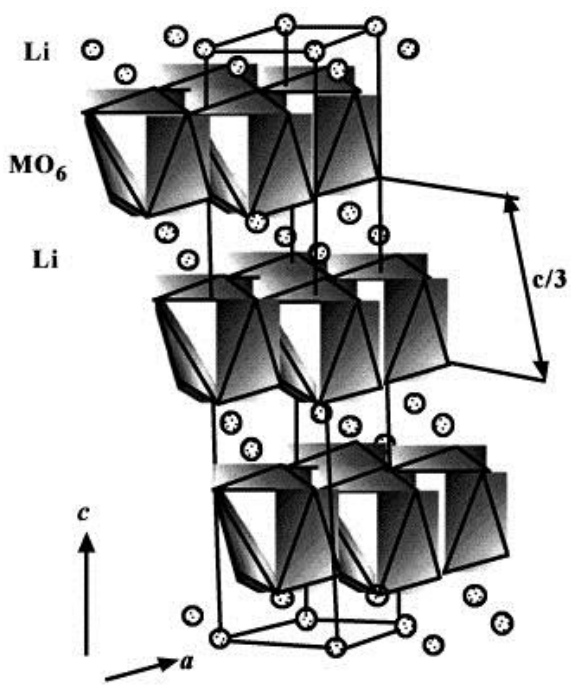

Fig. 1.

Schematic representation of the layered structure of $\mathrm{LiCo}_{1-} y \mathrm{Ni} \mathrm{O}_{2}$ compound. 
The layered structure of $\mathrm{LiCO}_{1-}-\mathrm{NNi}_{\mathrm{NO}} \mathrm{O}_{2}$ oxides has raised a considerable interest concerning their physicochemical properties, but there is confusion regarding the main results published in the literature along with the various interpretations of the magnetic properties. As for the electronic state of the $\mathrm{Ni}$ ion, several models have been proposed to explain some particular experimental results [4], [5] and [6]. However, there is a general agreement to consider that the $\mathrm{Ni}^{3+}$ ions are in low-spin state with an $S=1 / 2$. Recently, Barra et al. [6] have shown that magnetic properties of $\mathrm{Li}_{1-} Z \mathrm{Ni}_{1+} Z_{2} \mathrm{O}_{2}$ are driven by the zparameter. The compounds with high value of $z$ are described as ferromagnetic $\mathrm{Ni}-\mathrm{O}$ layers bridged by clusters possessing a net ferromagnetic moment.

In this work, we report on the electronic (electrical conductivity and EPR) and magnetic properties of nickel-rich $\mathrm{LiCo}_{1}-\mathrm{Niy}_{2}(y=0.8)$ powders synthesized by wet-chemistry method using succinic acid as chelating agent [7] and [8]. To characterise the samples, structural properties at subsequent stages of $\mathrm{Ni}$ substitution in $\mathrm{LiCo}_{1-} \mathrm{yNiyO}_{2}$ were done by X-ray diffraction and by FTIR spectroscopy. We obtained a good agreement between magnetic and resonance data (Fig. 2).

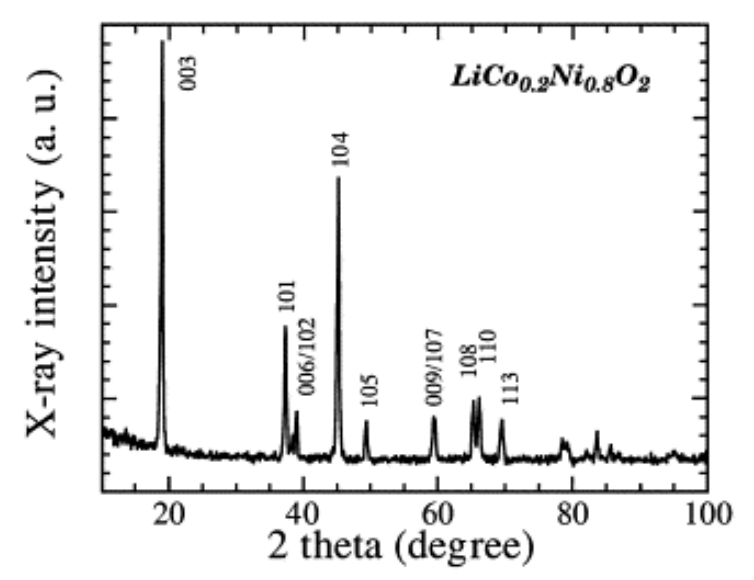

Fig. 2.

XRD diagram of $\mathrm{LiCo}_{0.2} \mathrm{Ni}_{0.8} \mathrm{O}_{2}$ grown by wetchemistry synthesis using succinic acid.

\section{Experimental}

Single-phase $\mathrm{LiCo}_{1-}-\mathrm{NiyO}_{2}$ compounds were obtained by wet-chemical method. The sol-gel process for preparation of $\mathrm{LiCo}_{1}-\mathrm{yNi}_{\mathrm{N}} \mathrm{O}_{2}$ oxides was similar to that described elsewhere [7]. Analytical pure metal acetates and carboxylic acid, namely succinic $\mathrm{C}_{4} \mathrm{H}_{6} \mathrm{O}_{4}$, were mixed and dissolved in distilled water to form a sol. Optimal synthetic conditions and the effect of molar ratio $(M / A)$ of total metal ions $(M=L i+C o+N i)$ to carboxylic acid $(A)$ on the physicochemical properties of $\mathrm{LiCo}_{1-} y \mathrm{Ni}_{\mathrm{y}} \mathrm{O}_{2}$ powders were investigated. Well-structured compounds were grown for the metal/acid ratio $M / A=1: 1$. 
The sol was evaporated to dryness at $80^{\circ} \mathrm{C}$ to form the gel. During this process, the mass precursor darkened progressively as a result of oxidation of divalent cations $\left(\mathrm{Ni}^{2+}\right.$, $\left.\mathrm{Co}^{2+}\right)$ to trivalent cations $\left(\mathrm{Ni}^{3+}, \mathrm{Co}^{3+}\right)$. The so-obtained ashes were heated at $400{ }^{\circ} \mathrm{C}$ during $2 \mathrm{~h}$, yielding brownish-black materials of submicrometer size. The powder mass was slightly ground and then fired at $800{ }^{\circ} \mathrm{C}$ for $2 \mathrm{~h}$ in air followed by a calcination in oxygen for $2 \mathrm{~h}$ to improve the crystallinity of $\mathrm{LiCo}_{1-} y \mathrm{NiyO}_{2}$ final products.

X-ray powder diffraction (XRPD) patterns were obtained with a D-5000 Siemens X-ray diffractometer, using nickel-filtered $\mathrm{CuK}_{\alpha}$ radiation $(\lambda=1.5406 \AA$ ). FTIR spectra were recorded at room temperature using an IFS113v Bruker interferometer equipped with a 3.5- $\mu$ m-thick beamsplitter, a globar source, and a DTGS/PE far-infrared detector. Composition of the final products was determined using a VG Plasma Quad II-S option induced-coupled-plasma mass-spectrometer. Elemental analysis data are summarized inTable 1. These results clearly indicate that $\mathrm{LiCo}_{1}-\mathrm{yNiyO}_{2}$ oxides synthesized by the succinic acid method have a composition near the nominal stoichiometry. Similar results were obtained by Rietveld refinement of XRPD data.

Table 1.

Results of the elemental analysis (ICP data) of $\mathrm{LiCo}_{1-} y \mathrm{Ni}_{\mathrm{N}} \mathrm{O}_{2}$ samples

Experimental (succinic samples)

\begin{tabular}{llll} 
Nominal composition & $\mathrm{Li}$ & $\mathrm{Co}$ & $\mathrm{Ni}$ \\
\hline $\mathrm{LiCoO}_{2}$ & $0.99 \pm 0.02$ & $1.00 \pm 0.03$ & - \\
\hline $\mathrm{LiCo}_{0.80} \mathrm{Ni}_{0.20} \mathrm{O}_{2}$ & $0.98 \pm 0.02$ & $0.80 \pm 0.02$ & $0.20 \pm 0.01$ \\
$\mathrm{LiCo}_{0.60} \mathrm{Ni}_{0.40} \mathrm{O}_{2}$ & $1.01 \pm 0.02$ & $0.63 \pm 0.01$ & $0.41 \pm 0.01$ \\
$\mathrm{LiCo}_{0.40} \mathrm{Ni}_{0.60} \mathrm{O}_{2}$ & $1.00 \pm 0.01$ & $0.40 \pm 0.01$ & $0.61 \pm 0.01$ \\
$\mathrm{LiCo}_{0.20} \mathrm{Ni}_{0.80} \mathrm{O}_{2}$ & $1.00 \pm 0.01$ & $0.20 \pm 0.01$ & $0.83 \pm 0.02$ \\
$\mathrm{LiNiO}_{2}$ & $1.02 \pm 0.05$ & - & $1.03 \pm 0.05$
\end{tabular}

ESR measurements were performed at X-band frequencies $(\approx 9.25 \mathrm{GHz})$ using a Varian ESR spectrometer and a $\mathrm{TE}_{102}$ rectangular microwave cavity, in which an ESR9 Oxford Instrument continuous flow cryostat is inserted. This cryostat allowed measurements between $3.5 \mathrm{~K}$ and room temperature. Our powder samples were placed in a quartz tube which was purged with helium gas. 


\section{Results and discussion}

\subsection{Structural properties}

X-ray powder diffraction was used to identify the crystalline phase of the materials when powders were calcined at $800{ }^{\circ} \mathrm{C}(2 \mathrm{~h}$ in air and $2 \mathrm{~h}$ in oxygen). For $0 \leq y \leq 0.8$ Bragg peaks are indexed in the hexagonal crystallographic system (R3m space group) showing materials with a $\alpha-\mathrm{NaFeO}_{2}$-type structure [2] and [3]. The hexagonal lattice parameters, $a$ and $c$, were calculated by a least-squares refinement. The compositional dependence of the crystallographic parameters of $\mathrm{LiCo}_{1-} y \mathrm{NiyO}_{2}$ powders synthesized by sol-gel method using succinic acid are in good agreement with values reported in the literature [9] and [10] and they are characteristic features of the $\mathrm{LiCo}_{1}-y_{\mathrm{Ni}} \mathrm{NO}_{2}$ solid solution. It is worth pointing that a high value of the $c / a$ ratio $(c / a>4.95)$ and a clear splitting of the (006)-(102) and (108)-(110) Bragg lines as well as the intensity ratio $I_{(003)} / I_{(104)}>1$ have been acknowledged to be an indication, as far as XRD patterns are concerned, of an ordered distribution of lithium and transition-metal ions in the structure.

FTIR measurements were made to investigate the local environment of cations in a cubic close-packed oxygen array of the $\mathrm{LiCO}_{1-}-\mathrm{NiyO}_{2}$ lattice. Infrared modes correspond to vibrations involving primarily atomic motion of oxygen anions against their cationic neighbors [11]. Consequently, these modes are very sensitive to the cationic local environment in the host matrix. The FTIR absorption spectra of $\mathrm{LiCo}_{1}-\mathrm{yNi}_{\mathrm{NO}} \mathrm{O}_{2}$ of samples synthesized via succinic acid display the high wave number region, at ca. $400-600 \mathrm{~cm}^{-1}$, corresponding to the broad rock-salt band, which has broken into several distinct components. The bands located around $600 \mathrm{~cm}^{-1}$ are attributed to the asymmetric stretching modes of the $\mathrm{MO}_{6}$ group, whereas bands at ca. $400-500 \mathrm{~cm}^{-1}$ are assigned to the bending modes of the $\mathrm{O} \square \mathrm{M} \square \mathrm{O}$ bonds. The farinfrared region, in which an isolated strong band is centered at ca. $240-260 \mathrm{~cm}^{-1}$, is attributed to the vibration of elongated $\mathrm{LiO}_{6}$ octahedral groups. For succinic samples, as $\mathrm{Co}_{\mathrm{O}}$ is substituted for $\mathrm{Ni}$, the peak position shift toward the low wave number side and the peak intensity slightly decreases due to the increase of the electronic conductivity in Ni-rich samples. The shift of the band position to lower frequency against $\mathrm{Ni}$ content corresponds to features of a solid solution. However, the FTIR spectrum does not display the presence of $\mathrm{Ni}$ ions in $\mathrm{Li}$ predominant slabs of $\mathrm{LiCO}_{0.2} \mathrm{Ni}_{0.8} \mathrm{O}_{2}$ samples. 


\subsection{Magnetic properties}

The magnetization of the sample $\mathrm{LiCo}_{1}-y \mathrm{Ni} \mathrm{O}_{2}$ for $0.2 \leq y \leq 0.8$ was measured at room temperature with a vibrating sample magnetometer (VSM) and superconducting quantum interference device (SQUID) magnetometer. Results clearly exhibit a paramagnetic behavior. Fig. 3(a-b) shows the thermal variation of the magnetization profile of $\mathrm{LiCo}_{1}-y \mathrm{NiyO}_{2}$ samples synthesized by wet-chemistry using the succinic acid (1:1) as chelating agent for $y=0.80$ and $y=0.75$, respectively. For $\mathrm{LiCo}_{0.2} \mathrm{Ni}_{0.8} \mathrm{O}_{2}$ (Fig. $3(\mathrm{a})$ ), we clearly observed a change around $80 \mathrm{~K}$ in its magnetic behavior from ferromagnetic (or ferrimagnetic) to paramagnetic corresponding to the trivalent nickel ions in a low-spin configuration. In the low temperature range $(4 \leq T \leq 100 \mathrm{~K})$, the magnetization of the $\mathrm{LiCo}_{1-}-\mathrm{NNi}_{2} \mathrm{O}_{2}$ samples for $0.2 \leq y \leq 0.75$ still exhibits a paramagnetic behavior, while the sample for $y=0.8$ clearly exhibits a ferromagnetic behavior with hysteresis loop as shown in Fig. 3(a). The Curie temperature is estimated to be in the range $90 \leq T_{\mathrm{C}} \leq 100 \mathrm{~K}$. Saturating values of magnetization $M_{S}$ decrease with increasing temperature as presented in Table 2.

(a)

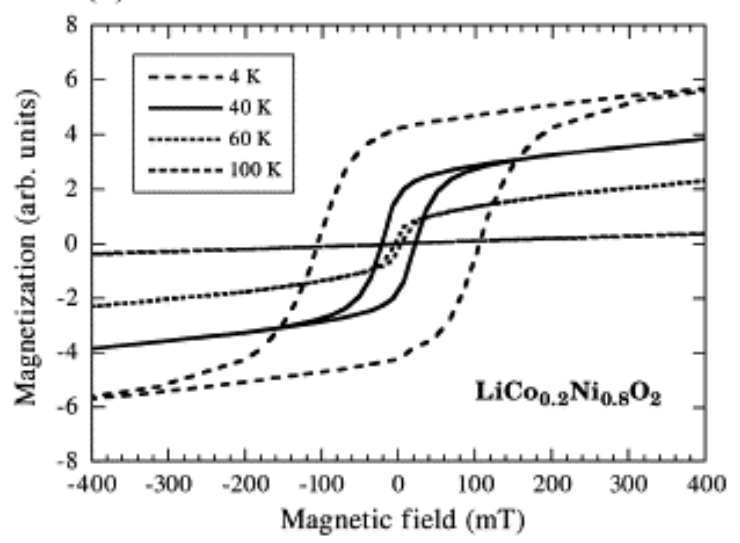

(b)

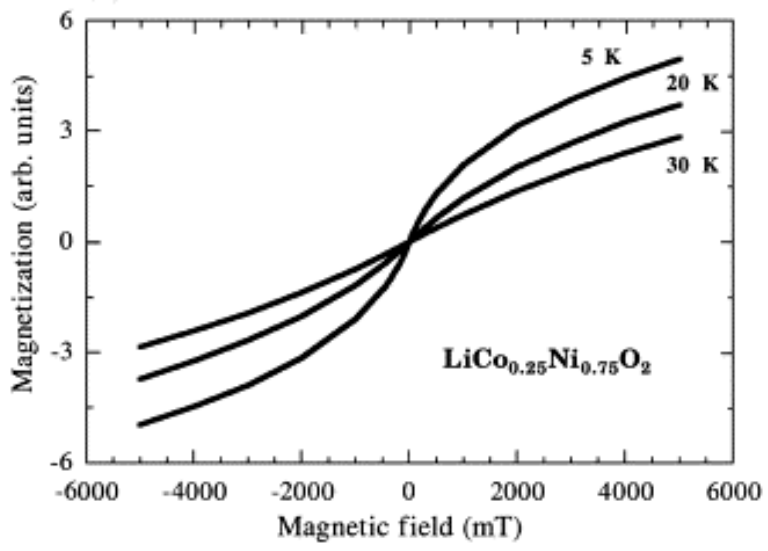

Fig. 3.

Temperature dependence of the magnetization profiles of (a) $\mathrm{LiCo}_{0.2} \mathrm{Ni}_{0.8} \mathrm{O}_{2}$ and (b) $\mathrm{LiCo}_{0.25} \mathrm{Ni}_{0.75} \mathrm{O}_{2}$ synthesized by wetchemistry method using succinic acid. 


\begin{tabular}{|c|c|}
\hline Temperature (K) & $\mathrm{M}_{\mathrm{s}}(\mathrm{emu} / \mathrm{g})$ \\
\hline 4 & 11.76 \\
\hline 40 & 11.33 \\
\hline 60 & 7.29 \\
\hline 100 & 1.06 \\
\hline
\end{tabular}

The magnetic susceptibility $X_{\mathrm{m}}$ was also measured in $\mathrm{LiCo}_{1}-\mathrm{yNi}_{\mathrm{N}} \mathrm{O}_{2}$ as a function of the temperature (Fig. 4). In the composition range $0.2 \leq y \leq 0.75$, the linearity of the reciprocal susceptibility $1 / X_{m}$ versus temperature is typical of a Curie-Weiss paramagnetism. This behavior means that the magnetic moments are localized in the samples for this range of nickel concentration. A drastic change is observed when the degree of nickel substitution for $\mathrm{Co}$ increases in $\mathrm{LiCO}_{1}-\mathrm{yNi}_{\mathrm{N}} \mathrm{O}_{2}$. Results show that a threshold value appears at $y=0.8$. For $\mathrm{LiCo}_{0.2} \mathrm{Ni}_{0.8} \mathrm{O}_{2}$ samples, the magnetic susceptibility diverges in the range $90 \leq T \leq 100 \mathrm{~K}$ as shown in Fig. 4(c). This behavior is characteristic of a longrange magnetic order. The extrapolation of the linear part of the $1 / X_{\mathrm{m}}$ curve gives the Curie temperature of $T_{\mathrm{c}}=95 \mathrm{~K}$. This property seems to be typical for samples prepared by wet-chemical synthesis, since it has not been observed on similar phases obtained by solid-state reaction of $\mathrm{NiO}, \mathrm{CoO}_{3}$ and $\mathrm{Li}_{2} \mathrm{CoO}_{3}$ followed by several thermal treatments [2] and [10]. 
(a)

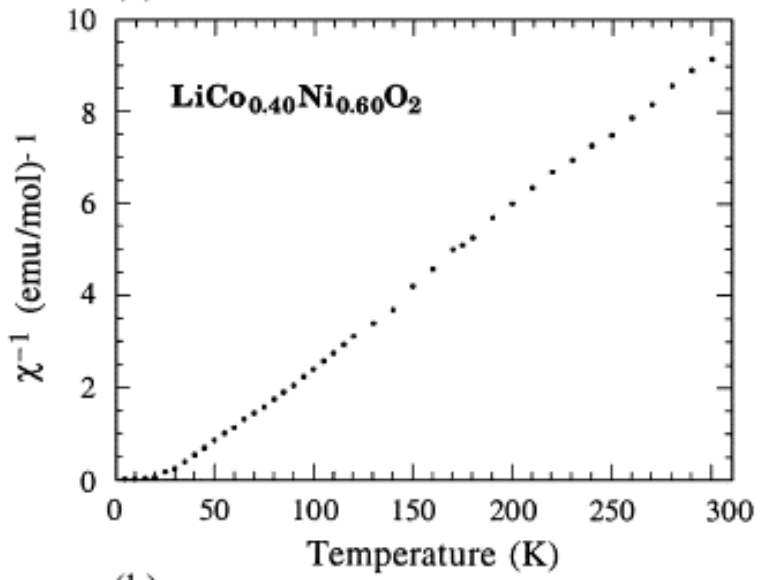

(b)

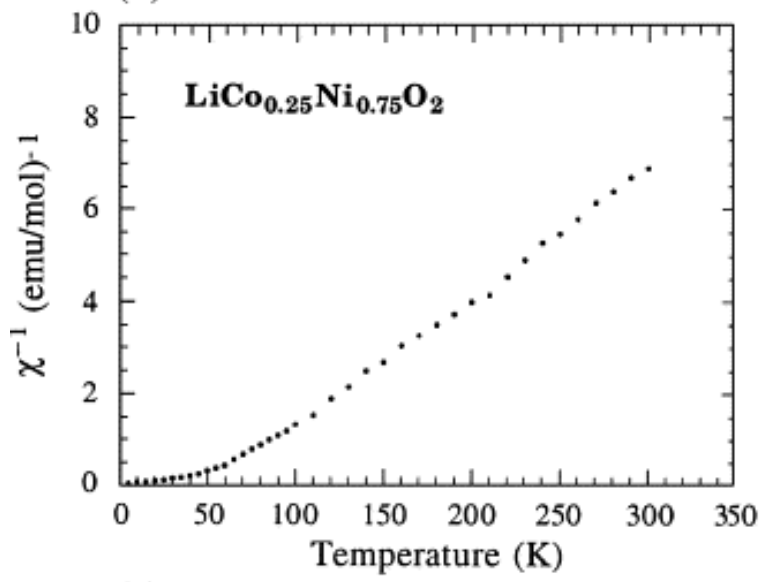

(c)

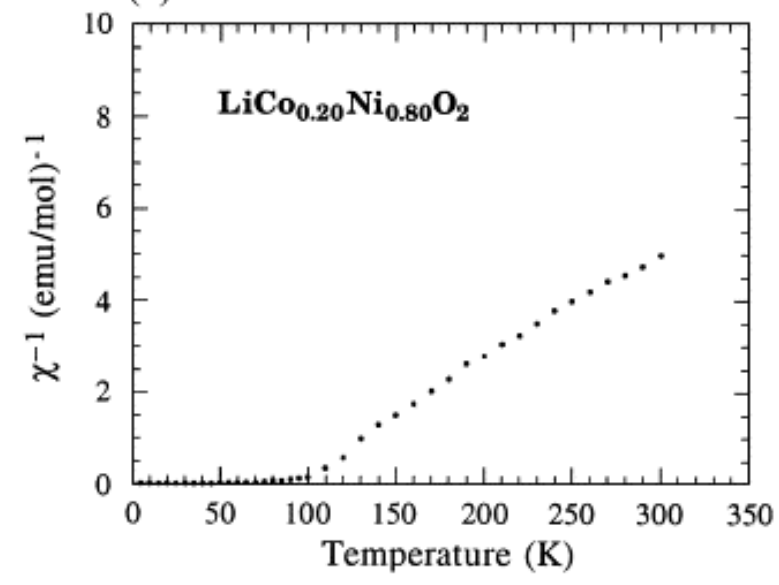

Fig. 4.

The reciprocal susceptibility $1 / X_{\mathrm{m}}$ as a function of the temperature in $\mathrm{LiCo}_{1}-\mathrm{NNi}_{2} \mathrm{O}_{2}$ powders synthesized by wetchemistry for (a) $y=0.60$, (b) $y=0.75$, and (c) $y=0.80$. Measurements were made at magnetic field of 50 Oe.

\subsection{Magnetic resonance properties}

To investigate further the magnetic properties of $\mathrm{LiCo}_{1-} \mathrm{yNiyO}_{2}$, we have also performed magnetic resonance experiments. Several magnetic resonance spectra have been reported on $\mathrm{LiCo}_{1-} \mathrm{yNiyO}_{2}$; the observed signals have been attributed to $\mathrm{Ni}^{3+}$ paramagnetic ions [5]. However, the authors investigated electron spin resonance 
(ESR) spectra in a narrow temperature range on materials elaborated by different synthesis methods.

Fig. 5 shows the electron-spin resonance spectra recorded at room temperature, for $\mathrm{LiCo}_{1-} y \mathrm{NiyO}_{2}$ samples (with $0.2 \leq y \leq 0.8$ ) synthesized by wet-chemistry using succinic acid $(1: 1)$ as the chelating agent. Spectra exhibit only one broad resonance line at about $320 \mathrm{mT}$. We remark that the line width increases with the degree of nickel substitution in $\mathrm{LiCo}_{1}-y \mathrm{Ni} \mathrm{O}_{2}$ from $\Delta B=90 \mathrm{mT}$ for $y=0.2$ to $\Delta B=226 \mathrm{mT}$ for $y=0.8$. In $\mathrm{LiCo}_{1-} y \mathrm{Niy} \mathrm{O}_{2}$ oxides, $\mathrm{Ni}^{3+}\left(3 \mathrm{~d}^{7}\right)$ ions located in octahedral crystallographic sites, with a low-spin state, have a spin 1/2. So, we observe the corresponding paramagnetic resonance transition due to these localized magnetic moments with a gyromagnetic factor $g=2.12$.

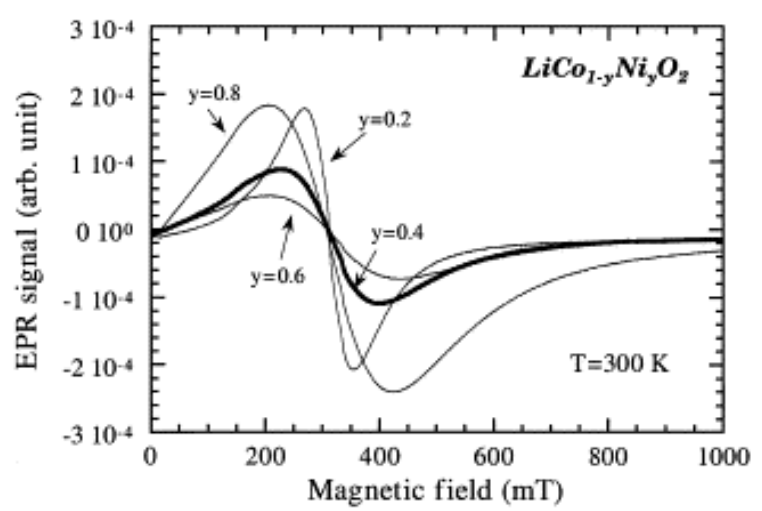

Fig. 5.

EPR spectra recorded at $300 \mathrm{~K}$ as a function of the composition $y(\mathrm{Ni})$ in $\mathrm{LiCo}_{1-1} \mathrm{yNi}_{2} \mathrm{O}_{2}$ synthesized by wet-chemistry.

At low temperatures, in the range $3.5 \leq T \leq 100 \mathrm{~K}$, we observe a large change in the ferromagnetic resonance (FMR) spectra when the amount of nickel ions increases in the $\mathrm{LiCo}_{1}-\mathrm{yNiyO}_{2}$ framework (Fig. 6). A single paramagnetic line is observed for $0.20 \leq y \leq 0.75$, while the powders are ferromagnetic for $\mathrm{LiCo}_{0.2} \mathrm{Ni}_{0.8} \mathrm{O}_{2}$, as indicated by magnetization and susceptibility measurements Fig. 3 and Fig. 4 . Thus, the value $y=0.8$ seems to be a compositional threshold. Fig. $7(a-b)$ presents the FMR detailed data for $\mathrm{LiCo}_{0.2} \mathrm{Ni}_{0.8} \mathrm{O}_{2}$. We observe three correlated lines at $T=40 \mathrm{~K}$ for this composition as shown in Fig. 7(a). The first line (I) located at very low magnetic field is typical of a process of magnetization by rotation along the hard magnetic axis of the particles [12]. This result brings an additional information on the ferromagnetic behavior of our sample $(y=0.8)$. The second line (II) and the third (III) band are typical FMR signals associated with a ferromagnetic resonance phenomenon in powder samples [13] and [14]. The line (II) located between 100 and $160 \mathrm{mT}$ is interpreted qualitatively as the resonance of particles having their easy magnetic axis aligned 
along the applied magnetic field. The third (III) observed at high magnetic field is attributed to the resonance associated with particles having their hard axis parallel to the applied field. The difference between the position of these two lines depends on the anisotropy field and the magnetization. So, this difference decreases with the increasing temperature from $1650 \mathrm{mT}$ at $3.5 \mathrm{~K}$ to $1000 \mathrm{mT}$ at $40 \mathrm{~K}$ and vanishes at $T_{\mathrm{c}}$.

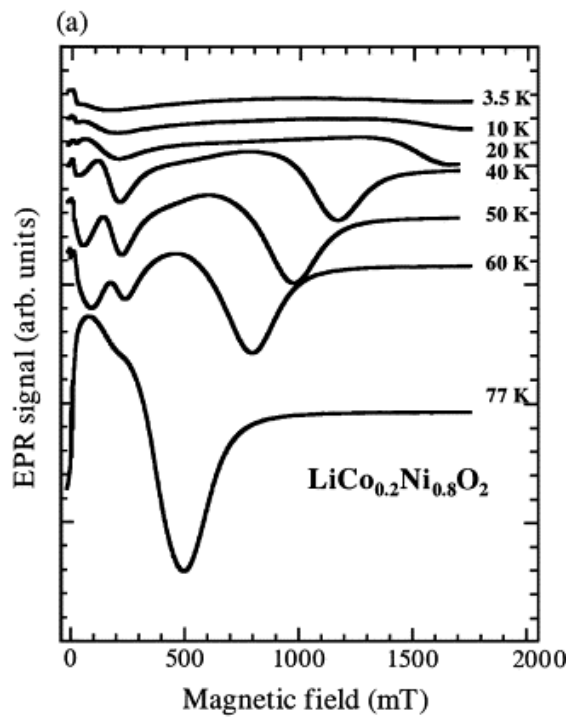

Fig. 6.

FMR spectra of $\mathrm{LiCo}_{0.2} \mathrm{Ni}_{0.8} \mathrm{O}_{2}$ powders as a function of the temperature in the range $3.5 \leq T \leq 260 \mathrm{~K}$.

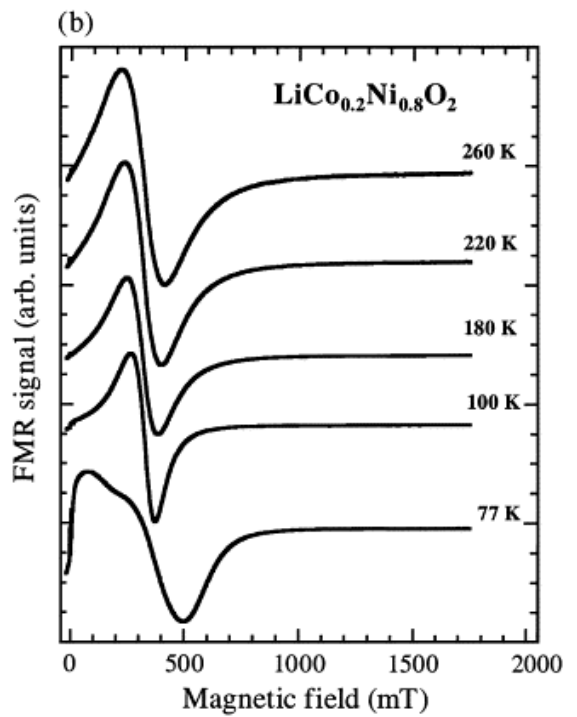




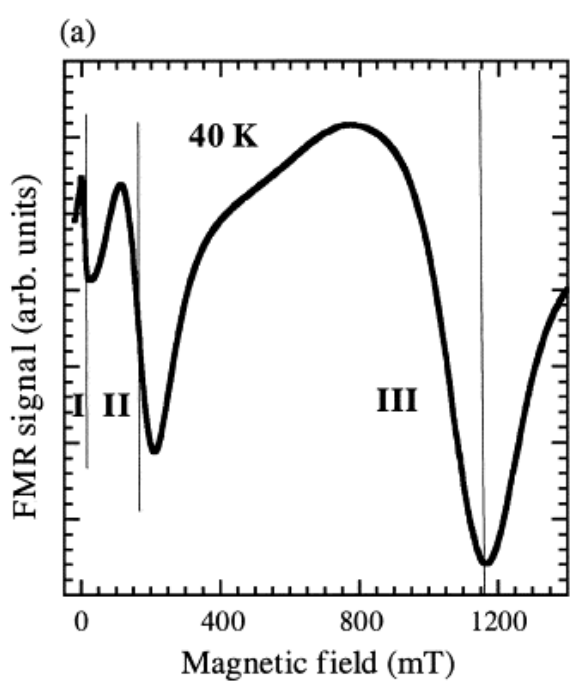

(b)
Fig. 7.

FMR spectra of $\mathrm{LiCO}_{0.2} \mathrm{Ni}_{0.8} \mathrm{O}_{2}$ powders showing the resonance details for (a) $40 \mathrm{~K}$ and (b) 3.5. K.

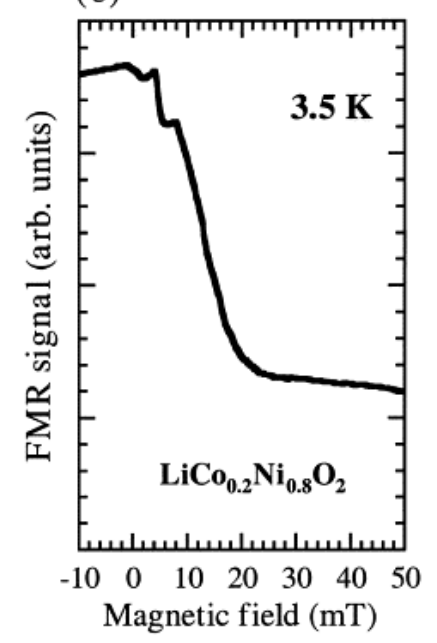

The long-range magnetic order observed in $\mathrm{LiNi}_{0.8} \mathrm{Co}_{0.2} \mathrm{O}_{2}$ can be discussed on the basis of crystallographic data and qualitatively well-described by the model proposed by Drillon and Panissod [15]for a ferromagnetic 3D order observed in hybrid compounds. In this model, the nature of the in-plane coupling of magnetic ions determines the existence of long-range magnetic ordering (Fig. 8). In the case where 2D ferromagnetic in-plane correlations dominate, and for a large interlayer spacing (more than $10 \AA$ ), these compounds exhibit a spontaneous magnetization, a characteristic ferromagnetic hysteresis loop and an ordering temperature around $20 \mathrm{~K}$. Such a large 3D ordering temperature cannot be explained by superexchange interaction but rather by dipolar through-space interaction between slabs. 


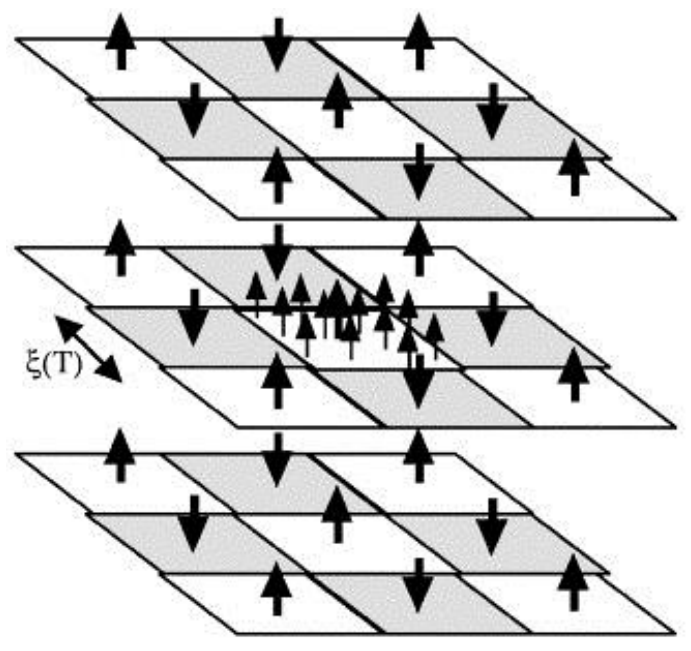

Fig. 8.

Model of the spin arrangement in ferromagnetic layers at non-zero temperature used for the calculation of the dipolar interaction. The side length $x$ of squares is the in-plane correlation length (after Ref. [15]).

For a 2D ferromagnet, the spins become only correlated on a finite length $\xi$ related to the exchange constant $J / k B$ and the spin value $S$ by the relationship

$\xi^{2}=\left(J S / k_{B} T\right) \exp \left(4 \pi J S^{2} / k_{B} T\right)$

and the corresponding magnetic susceptibility is given by

$\chi=(3 \pi J S)^{-1} \exp \left(4 \pi J S^{2} / k_{B} T\right)$.

The dipolar field created at a distance $d$ in the $c$-axis direction by the assembly of correlated spins is vanishingly small for $\xi \ll d$, but can reach a significant strength at low temperature as $\xi$ diverges. Correlatively, the magnetic susceptibility diverges as well. So, dipole interaction between moments located in different layers stacked along $c$-axis leads to $3 \mathrm{D}$ ordering, as soon as the in-plane correlation length reaches a threshold value related to the interlayer spacing and the in-plane spin density. The minimisation of the dipole and anisotropy energies requires that the order between slabs is ferromagnetic if $c$-axis is the local magneto-crystalline easy axis.

Crystallographic properties of our samples $\mathrm{LiNi}_{0.8} \mathrm{CO}_{0.2} \mathrm{O}_{2}$ are consistent with this model. Nickel and cobalt ions occupy the $\left(\mathrm{Ni}_{\mathrm{CO}} \mathrm{Co}_{1}-\mathrm{O}_{2}\right) n$ slabs. For $y=0.8$, the in-plane metalmetal distance has been measured: $a=2.88 \AA$ and the interlayer spacing $c^{\prime}=5 \AA$ with $c / a=4.93$. So, the nickel concentration $y=0.8$ corresponds to a threshold. For this degree of Co substitution, the in-plane exchange leads to a significant correlation length. The threshold value is the amount of $\mathrm{Ni}^{3+}$ ions which induces dipole interaction between moments located in the successive layers stacked along $c$-axis leading to a 3D magnetic ordering. 


\subsection{Electronic properties}

The Arrhenius plot of the electrical conductivity shows that the conduction in $\mathrm{LiCO}_{0.2} \mathrm{Ni}_{0.8} \mathrm{O}_{2}$ is thermally activated owing to the semiconducting character of this oxide as shown in Fig. 9. The electrical conductivity varies from $4 \times 10^{-4}$ to $0.25 \mathrm{~S} / \mathrm{cm}$ in the temperature range 120-580 K. All observed phenomena for the electronic transport can be ascribed to small-polaron conduction. This mechanism is clearly supported by the appearance of the Arrhenius $\sigma T$ plot curvature, the small value of the activation energy, ca. $0.07 \mathrm{eV}$, and the typical behavior of the ac measurements. It is assumed that the hopping process takes place between the highest oxygen valence band and the acceptor $\mathrm{M}^{3+} / \mathrm{M}^{2+}$ level [16]. The relatively low conductivity values of our

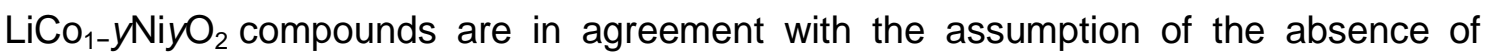
extra-ions in predominantly Li layers.

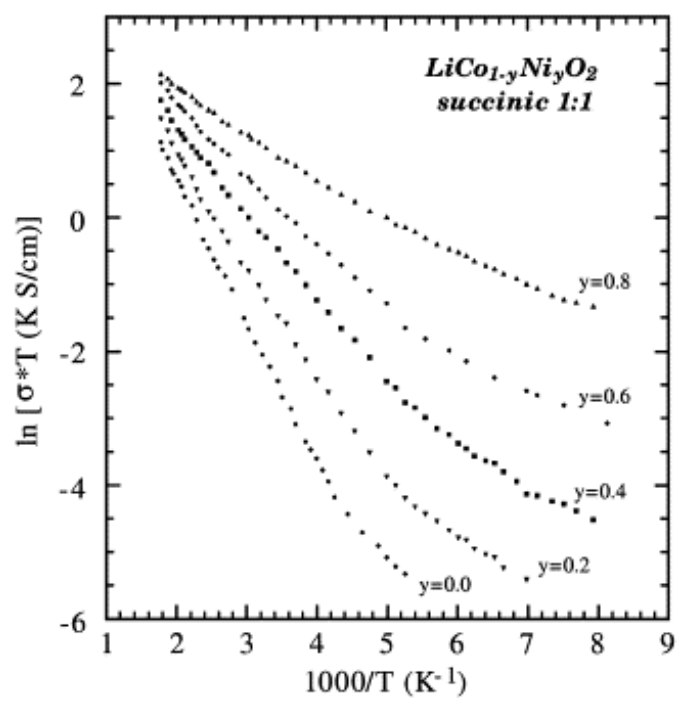

Fig. 9.

Arrhenius plots of the electrical conductivity of $\mathrm{LiCo}_{1}-y \mathrm{Ni}_{2} \mathrm{O}_{2}(0.0 \leq y \leq 0.8)$ synthesized by wetchemistry using succinic acid.

\section{Conclusion}

ESR technique is advantageous in exploring the electronic structure in $\mathrm{LiCo}_{1}-y \mathrm{NiyO} \mathrm{O}_{2}(0.0<y<1.0)$. For $\mathrm{LiCO}_{0.2} \mathrm{Ni}_{0.8} \mathrm{O}_{2}$, we observed several resonance lines as a function of the temperature in the range $3.5-300 \mathrm{~K}$. Three lines have been recorded at low temperature $(3.5 \leq T \leq 100 \mathrm{~K})$. The signal at low magnetic field is attributed to the magnetization of magnetic domains in the nanostructured sample. The two other lines correspond to the typical ferromagnetic resonance signal observed in powdered compounds. In the temperature range $120-300 \mathrm{~K}$, a unique ESR line centered at 315 $\mathrm{mT}$ is observed. As expected, its half-width increases linearly with temperature. This line is the paramagnetic signal with a gyromagnetic factorg $=2.12$, which is in good 
agreement with the presence of a high concentration of $\mathrm{Ni}^{3+}\left(3 \mathrm{~d}^{7}\right)$ ions. The magnetic properties observed in $\mathrm{LiNi}_{0.8} \mathrm{Co}_{0.2} \mathrm{O}_{2}$ are discussed on the basis of crystallographic data and qualitatively well-described by the model proposed by Drillon and Panissod [15] for a 3D ferromagnetic order.

\section{Acknowledgements}

The authors wish to thank Dr. A. Mauger for fruitful discussion. The financial support of the Spanish and French Foreign Office (HF 1999-0101, PAl Picasso 00717TC) is acknowledged.

\section{References}

1. ,in: C Julien, Z Stoynov (Eds.), Materials for Lithium-ion Batteries, NATO ASI Series, Ser. 3-85, Kluwer, Dordrecht (2000)

2. I Saadoune, C Delmas

J. Solid State Chem., 136 (1998), p. 8

3. H.J Orman, P.J Wiseman

Acta Crystallogr., C40 (1984), p. 12

4. K Hirota, H Yoshizawa, M Ishikawa

J. Phys.: Condens. Matter, 4 (1992), p. 6291

5. R Stoyanova, E Zhecheva, R Alcantara, P Lavela, J.L Tirado

Solid State Commun., 102 (1997), p. 457

6. A.L Barra, G Chouteau, A Stepanov, A Rougier, C Delmas Eur. Phys. J., B7 (1999), p. 551

7. C Julien, C Letranchant, S Rangan, M Lemal, S Ziolkiewicz, S Castro-Garcia, L El-Farh, M Benkaddour

Mater. Sci. Eng., B, 76 (2000), p. 145

8. C Julien

lonics, 6 (2000), p. 30

9. D Caurant, N Baffier, B Garcia, J.P Pereira-Ramos

Solid State lonics, 91 (1996), p. 45

10. I Saadoune, C Delmas

J. Mater. Chem., 6 (1996), p. 193 
11. C Julien

Solid State Ionics, 136-137 (2000), p. 887

12. M Rivoire, G Suran

J. Appl. Phys., 78 (1995), p. 1899

13. D.L Griscom

J. Non-Cryst. Solids, 42 (1981), p. 287

14. D.L Griscom

J. Magn. Reson., 45 (1981), p. 81

15. M Drillon, P Panissod

J. Magn. Magn. Mater., 188 (1998), p. 93

16. J.B Goodenough

Prog. Solid State Chem., 5 (1971), p. 145

Corresponding author. Tel.: +33-1-4427-4440; fax: +33-1-4427-3854 